\title{
POEMAS NA ESCOLA: ANÁLISE DE TEXTOS DE ALUNOS'
}

\author{
Maria da Graça Costa Val* \\ Beth Marcuschi**
}

RESUMO: Neste artigo, analisamos poemas elaborados em 2006 por alunos do Ensino Fundamental (com duração, à época, de oito anos), de quarta e quinta série de escolas públicas de vários estados brasileiros, no contexto do Programa Escrevendo o Futuro. Esse programa é desenvolvido pelo Centro de Estudos e Pesquisas em Educação, Cultura e Ação Comunitária - CENPEC, a partir de prêmio instituído pela Fundação Itaú Social. Mais do que um concurso de redação, o Escrevendo o Futuro se volta para a formação de professores, fornecendo às escolas inscritas fascículos com orientações para a realização de oficinas de produção de textos dos gêneros poema, memórias e artigo de opinião. A perspectiva deste trabalho é identificar como se apresentam os textos de alunos submetidos a um processo sistemático de formação quanto ao gênero em pauta. Para tanto, trazemos uma discussão inicial a respeito da noção de gênero textual, em seguida introduzimos o contexto em que as produções foram realizadas, para, na sequência, analisarmos os poemas dos alunos quanto à adequação ao gênero.

Palavras-chave: Produção Escrita; Gênero Textual; Poema.

\section{POEMS IN SCHOOL: ANALYSIS OF STUDENTS TEXTS}

ABSTRACT: In this study, we analyze poems written in 2006 by fourth and fifth graders from public elementary schools (8 years old at the time) from several Brazilian states, for the Programa Escrevendo o Futuro. This program, developed by the Centro de Estudos e Pesquisas em Educação, Cultura e Ação Comunitária - CENPEC, is part of a prize created and sponsored by the Itaú Social Foundation. More than a mere writing contest, Escrevendo o Futuro is a teacher training program, which provides the participating schools with guidance booklets for the development of writing workshops on the genres poem, memoir and opinion articles. The study's perspective is to identify how the texts are written by students undergoing a systematic learning process regarding a specific genre. With this purpose, we begin with an initial discussion on the conception of genre followed by a presentation of the context in which the texts were written, and then analyze the students' poems considering their adequacy to the genre.

Keywords: Written Production in School; Genre; Poem.

\footnotetext{
* Doutora em Educação pela Universidade Federal de Minas Gerais (UFMG); Professora aposentada da Faculdade de Letras da Universidade Federal de Minas Gerais (UFMG) e Pesquisadora do Centro de Alfabetização e Letramento (CEALE) da Faculdade de Educação da Universidade Federal de Minas Gerais (UFMG). E-mail: grcostaval@terra.com.br

* * Doutora em Linguística pela Universidade Federal de Pernambuco (UFPE); Professora da Graduação e Pós-Graduação do Departamento de Letras da Universidade Federal de Pernambuco (UFPE) e Pesquisadora do Centro de Estudos em Educação e Linguagem (CEEL) da Universidade Federal de Pernambuco (UFPE) e do Centro de Alfabetização e Letramento (CEALE) da Faculdade de Educação da Universidade Federal de Minas Gerais (UFMG). E-mail: beth.marcuschi@gmail.com
} 


\section{0 gênero textual no contexto didático: possibilidades e limites}

\subsection{Breves reflexões sobre a noção de gênero textual}

O estudo dos gêneros textuais não é recente. No mundo ocidental, ele se faz presente desde a obra de Platão, pelo menos, tendo se tornado, ao longo dos séculos, objeto de reflexão de filósofos e pensadores, que, no entanto, o relacionaram quase que exclusivamente ao estudo da constituição formal dos gêneros da esfera literária e, em parte, também de gêneros da instância de circulação de atos retóricos. A questão dos gêneros textuais é, nesse sentido, relativamente antiga, mas o enfoque hoje a ela atribuído é certamente bastante distinto.

Agora, além da noção de gênero textual extrapolar as esferas literária e retórica, passando a caracterizar toda manifestação verbal humana, ela não é tida apenas como uma expressão linguística, mas é estudada na sua inter-relação com as práticas sociais historicamente situadas. De fato, observa-se que, atualmente, os gêneros textuais constituem uma fértil área de investigação, com atenção especial para a linguagem em funcionamento, isto é, para o contexto das atividades socioculturais das pessoas. No Brasil, há significativa proliferação de trabalhos sobre o tema, muitos deles influenciados pelas concepções teóricas defendidas por Mikhail Bakhtin, outros apoiados nas reflexões elaboradas ou pela Escola de Sidney ou pela Escola de Genebra ou ainda pela linha da nova retórica americana ${ }^{2}$.

Segundo Marcuschi ${ }^{3}$ (2002), os gêneros textuais são os textos que encontramos em nossa vida diária e que apresentam padrões sociocomunicativos característicos, definidos por composições funcionais, objetivos enunciativos e estilos concretamente realizados. Para esse autor, os gêneros são atividades textuais escritas ou orais bastante estáveis, histórica e socialmente situadas, e que se expressam em designações diversas (conto, carta, reportagem, crônica, sermão, bula de remédio, horóscopo, lista de compras, inquérito policial, poema, instruções de uso, lenda, piada, fábula, conferência, receita culinária, e-mail, etc.), constituindo, em princípio, listagens abertas.

Miller ${ }^{4}$ (1994 [1984]), entre outros estudiosos, ratifica esse enfoque e defende a noção de gênero textual enquanto uma "forma de ação social". Para a autora, quando dominamos um gênero textual não dominamos uma forma linguística e, sim, uma forma de realizar linguistica- 
mente objetivos específicos em situações sociais particulares. Na mesma linha, para Bronckart ${ }^{5}$ (1999, p. 103), “a apropriação dos gêneros é um mecanismo fundamental de socialização, de inserção prática nas ativida-

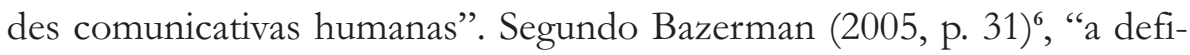
nição de gêneros como apenas um conjunto de traços textuais ignora o papel dos indivíduos no uso e na construção de sentidos. Ignora as diferenças de percepção e compreensão, o uso criativo da comunicação" para abandonar antigas ou satisfazer novas necessidades das práticas sociais ao longo da história.

Em sintonia com as posições aqui explicitadas, defende-se, neste artigo, que toda interação verbal é efetivada pelos usuários no interior de uma prática social, por sua vez culturalmente tipificada pelos gêneros textuais que nela circulam. Daí decorre muito claramente a centralidade da noção de gênero textual no trato sociointerativo da elaboração linguística do ser humano, pois toda ação de linguagem implica a produção e a compreensão histórica e socialmente contextualizada de gêneros textuais.

Como sublinha Marcuschi (2002), a aprendizagem de um gênero textual por parte dos usuários requer, para além do conhecimento de sua forma linguística, também o domínio de sua função comunicativa, do que ele permite enunciar com mais propriedade do que outros gêneros, de suas condições de produção, bem como das práticas em que ele circula. Assim, ser proficiente em determinado gênero textual envolve, primordialmente, o conhecimento da complexidade de sua realização nos contextos interacionais.

A perspectiva de estudo dos gêneros textuais aqui brevemente delineada coloca para a escola o desafio de trabalhar (BUNZEN, 2004) ${ }^{7}$ não mais o sentido homogêneo, o uno, mas o plurilinguismo, o heterogêneo, não mais os gêneros textuais como atemporais e transparentes, mas como entidade empírica de organização dos discursos, comunicativa, de natureza altamente maleável, dinâmica e plástica.

Algumas das tarefas da escola são, nesse sentido, oferecer respostas às demandas postas pela sociedade contemporânea e ensinar aos alunos a escrita de textos ${ }^{8}$ sem descuidar de sua relação com as práticas constitutivas da ação humana. Esse encaminhamento pressupõe, como sugere Rojo (2008) ${ }^{9}$, uma noção de língua como atividade, ação interacional, e, além disso, práticas pedagógicas plurais e atentas tanto à multimodalidade quanto à intertextualidade e à variação linguística, aspectos que as teorias de gêneros textuais favorecem. 


\subsection{A produção de textos escritos no espaço extraescolar e no contexto escolar}

No espaço extraescolar, ao produzir um texto, o autor, via de regra, tem em vista, mesmo que inconscientemente, as condições colocadas pelas práticas em que o texto vai circular. Considera, por exemplo, para quem, quando, sobre o que, com que objetivo escreve. Essas características contribuem para que o escritor se defina pelo gênero textual mais adequado ao contexto. Por exemplo, se um consumidor quiser prestar queixas junto a uma revendedora de automóveis, uma "receita de cozinha" não será o gênero textual mais indicado. Nesse caso, a "carta de reclamações" seria, certamente, mais interessante. Por sua vez, uma "carta de reclamações" não surtirá muito efeito se a pessoa deseja ver seu texto circular na coluna Opinião de algum jornal ou revista. Nesse contexto, o mais recomendado seria a elaboração de um "artigo de opinião". Do mesmo modo, um "artigo de opinião" não cumprirá a função sociocomunicativa pretendida, se um astrólogo se propuser indicar para as pessoas suas perspectivas futuras. Aqui, um "horóscopo" seria mais aconselhável, e assim por diante... ${ }^{10}$ É também em função do contexto sociocomunicativo e do leitor presumido que o autor se decide pelo "tom" que deseja imprimir ao seu texto: se formal ou coloquial, se irritado ou benevolente, se irônico ou conciliatório, entre outras possibilidades. Como se percebe, é esse caráter situado do trabalho de escrita que o caracteriza como atividade dialógica, cultural, desenvolvida por um produtor ativo, que empreende esforços para atingir objetivos no espaço social.

Historicamente, na escola, a demanda do texto a ser redigido pelo aluno costuma responder a um objetivo pedagógico, visando a uma aprendizagem específica. A motivação do aluno no desenvolvimento do texto escrito é, sobretudo, satisfazer às exigências estabelecidas pelo professor.

Em vista disso, as condições de produção não costumam ser indicadas na sala de aula. Rotineiramente, as atividades se atêm à menção de um gênero escolarizado (narração, descrição, dissertação) e/ou ao tema a ser desenvolvido. Com isso, os enunciados recomendam, por exemplo, que o aluno: "escreva uma história sobre um piquenique na praia"; "descreva seu animal de estimação"; "argumente a favor ou contra a venda de guloseimas na cantina da escola"; "redija um texto sobre a festa da Páscoa", etc. Em decorrência, o texto fica restrito à esfera escolar e tem como objetivo principal e, muitas vezes, único, preencher um exercício de 
escrita. O leitor do texto do aluno, por sua vez, reduz-se ao professor ou, eventualmente, ao colega, que têm a missão de encontrar os "defeitos" do texto e não de interagir com ele. Em consequência, o texto tende a se caracterizar por sua precariedade dialógica e, assim, pouco contribui para que o aluno atribua à escrita um sentido social ou mesmo para que ele aprenda a se submeter à crítica de leitores externos.

É nessa conjuntura, afirma Rojo (2008), que a noção de gênero textual é (re)convocada para revigorar as práticas pedagógicas. Isso porque o trabalho com os gêneros textuais oferece possibilidades para que o encaminhamento tradicional seja revisto. "E por que esta noção e não outra? Em primeiro lugar, porque, como nota Marcuschi (2002, p. 23), diferentemente dos tipos de texto, os gêneros de discurso/texto não são construtos teóricos definidos por propriedades linguísticas intrínsecas, mas realizações linguísticas concretas definidas por propriedades sócio-comunicativas. Portanto, diferentemente da noção de tipo, a de gênero, em princípio, favorece um tratamento mais flexível da forma e do estilo e o diálogo entre linguagens e vozes na construção dos sentidos situados ou contextualizados. É mais resistente, em princípio, à gramaticalização (ROJO, 2008, p. 92).

Concordando com os autores, cabe acrescentar que trabalhar com gêneros não significa transformá-los em objeto de prescrição, mas de reflexão. De nada adianta, pois, realizar um estudo que se atenha apenas à exploração das características estruturais do gênero textual, ainda que estas não devam ser ignoradas. Na perspectiva de tomar a elaboração textual como objeto de ensino, é fundamental que professor e aluno estejam familiarizados com a função social do gênero textual a ser produzido, com as condições de produção a serem consideradas e com as práticas em que ele predominantemente circula. O usuário proficiente no gênero "notícia”, por exemplo, não apenas reconhecerá seus traços mais característicos, mas saberá distinguir, em função de diversas "pistas" contextuais e discursivas, se aquela é uma notícia sensacionalista, conservadora ou progressista, entre outras possibilidades.

Outro ponto que merece ser visto com cuidado é a familiaridade do aluno com a temática a ser contemplada, caso contrário o aprendiz poderá conhecer as características do gênero textual trabalhado, mas não terá o que dizer. Além disso, tal como ocorre no contexto extraescolar, durante todo o processo de escrita não pode ser esquecido o trabalho de planejamento, geração de ideias, escrita, revisão de trechos do texto, reto- 
madas, reescrita, revisão geral, até a produção final do texto que será publicizado.

Ainda que o gênero textual a ser elaborado na sala de aula configure sempre uma didatiz̧ação do gênero proveniente do espaço extraescolar (esse é o maior limite do trabalho com a escrita na escola), o estudo dos gêneros, se bem-conduzido, pode atuar efetivamente na formação de um aluno produtor de textos crítico e autônomo. É também com base na noção de gênero, sobretudo, que o texto escrito é agora tomado como objeto de ensino e de aprendizagem. Assim, no encaminhamento pedagógico da escrita, há a preocupação com o ensino e a aprendizagem das características textuais e discursivas de diferentes gêneros, procedimento que se distancia de uma elaboração descontextualizada de textos. Há igualmente a compreensão de que a atividade de escrita precisa fazer sentido para o aluno, na medida em que a apropriação dos gêneros textuais se constitui num mecanismo poderoso de inserção nas atividades comunicativas humanas, como pleiteia Bronckart (1999).

Nesse contexto, adquire relevância o princípio de que não se aprende a escrever simplesmente escrevendo, mas refletindo criticamente sobre as escolhas feitas ao longo do processo de escrita, por sua vez guiadas pela prática social em que o gênero textual circula.

As reflexões até aqui desenvolvidas crescem em importância quando se constata que o trabalho de formação dos alunos, via fascículos, do Programa Escrevendo o Futuro (PEF) está organizado por gênero textual, a saber: memórias, artigo de opinião ${ }^{11}$ e poesia. De fato, para o PEF, o gênero textual deve ser tomado como eixo principal no ensino da escrita de textos. Com base nesse eixo, os fascículos organizam as orientações sobre como encaminhar o trabalho de produção textual em sala de aula, aspecto que será comentado no próximo item.

\section{0 PEF 2006 e as orientações do fascículo Poetas da escola ${ }^{12}$}

O Programa Escrevendo o Futuro (PEF) 2006 tinha como perspectiva básica impulsionar a capacidade de escrita de crianças e jovens matriculados nas quartas e quintas séries (quinto e sexto anos, no atual Ensino Fundamental de 9 anos) das escolas públicas municipais brasileiras, bem como favorecer a formação continuada dos professores que 
atuam nessa etapa do Ensino Fundamental. De modo a ampliar a participação de alunos e docentes no Programa, o PEF instituiu entre suas ações o Prêmio Escrevendo o Futuro. Para se candidatar ao prêmio, o aluno deveria escrever, sob a orientação de seu (sua) professor/a, um texto que atendesse, entre outros aspectos, a um dos três gêneros textuais indica$\operatorname{dos}^{13}$ e ao tema "O lugar onde eu vivo".

O fascículo Poetas da escola parte do pressuposto de que os alunos já estão familiarizados com o gênero poema. Nesse contexto, cabe destacar que a noção de poema assumida pelo PEF se esgota na compreensão de poema como gênero lírico. As atividades que encaminham a tarefa de elaboração do poema estão mais voltadas para o mundo interior do alunopoeta, para a expressão de seu sentimento pessoal a respeito do cotidiano e do entorno, para a escolha das palavras, sem enfatizarem suficientemente seu contexto enunciativo de produção e de circulação. Nesse sentido, as atividades propostas pelo PEF deixam de considerar a complexidade do gênero poema e de dimensioná-lo no interior de uma prática social vista de uma perspectiva histórica e cultural, aspectos bastante relevantes para a compreensão e produção desse e de outros gêneros textuais. Pode-se dizer que a perspectiva básica do PEF, no fascículo, não é a de apresentar o gênero à criança, mas a de ampliar a abordagem de poema supostamente presente em seu cotidiano. Nesse sentido, intensifica o envolvimento do aluno com uma poeticidade que se alimenta, sobretudo, da riqueza no uso das palavras. Assim, pressupõe que, na cultura brasileira, é comum o convívio das crianças com textos poéticos, tais como parlendas, trovas ou quadrinhas, entre outras possibilidades. Por outro lado, não pode deixar de ser destacado que o material procura também desmistificar a ideia de que escrever poemas é fácil e se reduz à tarefa de agrupar um conjunto de palavras que rimam. Daí a relevância de certas "dicas" oferecidas ao professor, como a que alerta: "muitas vezes os alunos ficam tão preocupados em encontrar palavras que rimam que se esquecem de verificar se o verso construído transmite ao leitor uma idéia, sentimentos ou sensação. Você pode e deve conversar com eles a respeito" (Poetas da Escola, 2006, p. 30).

De forma a efetivar o seu propósito, a preocupação inicial do fascículo é estimular a leitura de textos literários, no caso, poemas, dos mais diversos tipos, a fim de que o aluno desenvolva uma compreensão variada do fenômeno literário e maior sensibilidade para a escuta e produção de determinado tipo de poemas. As Oficinas propostas no desenrolar 
das sequências didáticas prevêem tanto o resgate da experiência dos alunos com o gênero poema (sempre especificamente o lírico) como a reflexão sobre várias características do poema, visando à posterior produção, com uso dos recursos estudados.

\section{Os poemas dos alunos: adequação ao gênero ${ }^{14}$}

Neste item, uma amostragem dos poemas elaborados pelos alunos é analisada em termos de sua adequação ao gênero poema, visto aqui em sua perspectiva lírica, tal como proposto na atividade de escrita para os alunos. Quatro categorias foram tomadas como critério na verificação dessa adequação, nos 250 textos da amostra. É importante deixar claro que, ao indicarmos as categorias, trazemos para a análise os aspectos mais valorizados pelo fascículo do PEF (inclusive a dicotomia conteúdoforma), pois foram eles que, por terem sido intensamente trabalhados no decorrer das oficinas, certamente mais influenciaram a escrita dos poemas pelos estudantes.

A primeira delas foi a poeticidade, considerada tanto com relação ao tratamento poético do tema quanto ao trabalho criativo com a forma. No primeiro caso, levou-se em conta a recriação poética da realidade, por meio de metáforas, comparações e outras figuras de linguagem; no segundo caso, a utilização de recursos formais especiais, como a repetição e a aliteração. Não se ignora aqui a complexidade da noção de poeticidade, objeto de intensos debates e posições controversas no âmbito da teoria da literatura, inclusive no que tange ao esforço de superação da dicotomia conteúdo-forma. Uma discussão mais aprofundada a respeito, no entanto, demandaria um percurso relativamente longo, que não cabe no âmbito deste artigo.

A segunda subcategoria eleita foi a pessoalidade, entendida como a expressão subjetiva que registra o trabalho de autoria e se manifesta na capacidade de surpreender, pela presença de imagens inusitadas, pela criticidade, pelo humor, pelo jogo intertextual. A essa compreensão da pessoalidade se contrapôs o uso abusivo de clichês e lugares-comuns, geralmente associado à idealização do tema focalizado (“O lugar onde vivo”).

As duas últimas categorias foram a presença e a qualidade da rima e da métrica ou do ritmo, recursos formais encontrados em quase todos os textos. 
Foi feita, inicialmente, uma análise quantitativa, cujos resultados são sintetizados no Quadro 1, a seguir.

\begin{tabular}{|c|c|c|c|c|c|}
\hline \multirow{3}{*}{$\begin{array}{l}\text { Qualidade da } \\
\text { realização }\end{array}$} & \multicolumn{4}{|c|}{$\begin{array}{l}\text { QUADRO } 1 \\
\text { A PONTUAÇÃO SEGUNDO A } \\
\text { ÃO QUANTITATIVA DO ESTUDO }\end{array}$} & \multirow[b]{3}{*}{ Métrica } \\
\hline & \multicolumn{2}{|c|}{ Poeticidade } & \multirow{2}{*}{$\begin{array}{c}\text { Pessoalidade } \\
\text { (presença do } \\
\text { inusitado) }\end{array}$} & \multirow[b]{2}{*}{ Rima } & \\
\hline & $\begin{array}{c}\text { Recriação } \\
\text { do real }\end{array}$ & $\begin{array}{l}\text { Criação } \\
\text { formal }\end{array}$ & & & \\
\hline Nula, ausente & $78 \%$ & $80 \%$ & $36 \%$ & $7 \%$ & $19 \%$ \\
\hline Precária & $17 \%$ & $16 \%$ & $39 \%$ & $65 \%$ & $53 \%$ \\
\hline Razoável & $5 \%$ & $4 \%$ & $21 \%$ & $26 \%$ & $26 \%$ \\
\hline Adequada & $0 \%$ & $0 \%$ & $4 \%$ & $2 \%$ & $2 \%$ \\
\hline
\end{tabular}

Observando-se o Quadro 1, visualiza-se o resultado mais significativo e desconcertante: o critério mais importante, considerado marca decisiva e indispensável do gênero - a poeticidade -, foi o que apareceu na amostra com menor frequência; já a presença de rimas, dispensável, dada a existência de poemas com versos brancos, foi o quesito mais frequente nos textos examinados.

Poucos são os casos em que se constata um trabalho de linguagem que resulte em recriação da realidade, pela construção de imagens poéticas a partir da comparação e da metáfora ou de outras figuras, como a antítese e a metonímia, que aparecem em alguns textos. Apenas $22 \%$ da amostra apresentam algum grau de recriação do real (cf. Quadro 1), sendo que em $17 \%$ dos poemas a realização desse quesito é precária e em $5 \%$, ela não passa de razoável, de acordo com a análise feita. Menos frequentes ainda são os textos que se valem de recursos formais como a aliteração, a assonância, a repetição de versos e construções sintáticas: o total é de $20 \%$ da amostra, aparecendo em 16\%, realização precária, e em 4\%, realização razoável desse item (cf. Quadro 1).

À grande parte dos textos falta "encanto"; eles se mostram prosaicos - na seleção dos aspectos focalizados do tema e/ou no tratamento descritivo ou expositivo dado a eles. A linguagem é empregada, sobretudo, na chamada "função denotativa"; a conotação, quando presente, vem a serviço de lugares-comuns, de clichês gastos e previsíveis, que já perderam a possibilidade de sugerir e encantar. Apresentamos a seguir um exemplo representativo. 


\section{Exemplo $1(\mathrm{P} 101)^{15}$}

Em agosto a cidade de Chapecó

Completa 89 anos de uma história

de tragédias, crescimento

alegrias e prosperidade...

(...)

Crescimento, por ser

uma cidade pólo

de muitas famílias que aqui

chegaram... fazendo a cidade ser

um dos maiores índices

de crescimento do país... (...)

Outro exemplo de texto em que o tom e o conteúdo prosaicos suplantam a possível poeticidade é transcrito e comentado a seguir.

\section{Exemplo 2 (P230)}

O lugar onde eu vivo é muito especial

Se você for conhecer, vai achar muito legal

Tem muita animação

Se você andar por aqui vai sentir muita emoção

(...)

Onde eu vivo é muito especial

Com muita gente legal

Tem paisagem natural

A natureza espalha sem igual

São comuns na amostra casos como o do poema 230, que não traz qualquer traço de metaforização e apresenta clichês e rimas fáceis, pobres quanto às possibilidades de significação.

Já no poema 194, como em outras numerosas ocorrências, é o constrangimento da rima que prejudica a poeticidade e até mesmo a construção da coerência textual.

\section{Exemplo 3 (P194)}

$\mathrm{Na}$ cidade onde moro, paranaense toma chimarrão

Mas na cidade onde nasci, paulista, não toma não

Eu moro no meio, que é o centro 
Lá tem feira onde vende coentro

Eu moro nas três casas, a minha é a do meio

Lá na minha casa, não tem ninguém feio.

A rua é estreita e quando faz sol

A meninada joga futebol

Minha vizinha tem um animal

É um cão que faz au, au...(...)

Nesse texto, parece que a obrigação de fazer rimas, compreendida como característica imprescindível ao gênero, obscurece a necessidade de trabalho estético de recriação do real. Isso é que deve justificar escolhas tão inadequadas como "Eu moro no (...) centro/ Lá tem uma feira que vende coentro" e "Minha vizinha tem uma animal/ É um cão que faz au, au". Nesse caso, além do efeito de perda da poeticidade, a busca de rima como valor em si tem como consequência versos desconexos e um texto de unidade temática frágil.

Mas não há só textos sem poeticidade na amostra. Apontamos um dos exemplos em que imagens singelas, compostas por metáforas e antíteses, recriam o real e conferem encanto ao poema. Merece atenção o título, já em si metafórico e sugestivo: "Meia lua".

\section{Exemplo 4 (P175)}

\section{Meia Lua}

Enquanto muitos sonham em ir à lua,

Nós aqui patinamos pelas calçadas da rua, Jogando bola, empinando pipa e soltando pião,

Sonhando cada um em ser um grande campeão.

Criança na praça corre atrás da pombinha

Traduzindo pureza e magia.

Num mundo em guerra,

Num milênio que inicia

Só o milagre da vida,

Pra resgatar a Harmonia.

Quanto aos recursos formais (além da rima e do ritmo), entre os $20 \%$ de textos da amostra que os utilizam (16\% com realização precária e 
só 4\% com realização razoável), o mais frequente é a repetição de versos ou construções sintáticas, sobretudo nos poemas que tomam como título e refrão o tema do concurso (ou alguma forma variante): "o lugar onde eu vivo", ou "no lugar onde eu vivo", ou "no lugar onde eu moro", entre outras.

A repetição é um recurso menos sofisticado que a aliteração, o que deve explicar sua frequência mais alta na amostra. Esse uso, segundo o Dicionário eletrônico Houaiss da língua portuguesa (versão 1.0.5a), no verbete "refrão", faz parte da tradição oral e é conhecido e valorizado na cultura popular. Apesar da recorrência desse recurso "fácil", há também na amostra exemplos de uso da repetição conferindo poeticidade ao texto, como se vê em P240, a seguir:

\section{Exemplo 5 (P240)}

O meu bairro

Se todas as pessoas

Do meu bairro

Quisessem dar as mãos

Não haveria roubos,

Não haveria ladrão.

Se todas as pessoas

Do meu bairro

Quisessem ser feliz

Não haveria rancor,

Não haveria cicatriz.

Se todas as pessoas

Do meu bairro

Quisessem aprender

Não haveria pessoas,

$\mathrm{Na}$ rua para sofrer.

O outro recurso de criação formal apontado no fascículo Poetas da escola 2006 é a aliteração, que aparece com menor frequência nos poemas. Um dos raros exemplos foi flagrado nos versos "terra fértil, fibra forte/ o sisal nos emancipou", do poema 178.

Aliada à esgarçada ou ausente elaboração da poeticidade, vem a nula (36\%) ou frágil (39\%) expressão da pessoalidade em 75\% dos poemas (cf. Quadro 1). Num gênero que se configurou historicamente como "lírico", 
como manifestação do "eu poético", a ausência desse traço pode ser descaracterizadora.

$\mathrm{Na}$ análise, tomamos a pessoalidade por oposição ao clichê, à idealização que apenas reproduz o senso comum relativo aos conceitos de belo e bom em termos de lugar para se viver, ainda que não se possa aplicar a lugar nenhum. Em vez do clichê, previsível e impessoal, valorizamos a presença do inusitado, seja na seleção dos objetos de atenção, seja na postura diante do lugar tematizado no poema - um tratamento crítico ou humorístico - além do poético, já contemplado no item anterior.

Entretanto, é alta a frequência de poemas que trazem idealizações inespecíficas, que não caracterizam lugar nenhum. Entre os muitos exemplos possíveis, trazemos um caso para ilustrar essa afirmação. É o poema 21, em que não se verifica qualquer tratamento poético e personalizado do tema, prevalecendo o clichê "em estado bruto":

\section{Exemplo 6 (P21)}

O lugar onde vivo

Tem flores a perfumar

Uma longa estrada

A qual um dia irei passar.

(...)

O lugar onde vivo,

É repleto de natureza

E sou privilegiada

Pela sua beleza.

É verdade que, ampliando-se o sentido de pessoalidade e atribuindo-lhe a significação dada pelo senso comum, diríamos que o ponto de vista adotado pelo aluno autor é sempre pessoal, sendo a subjetividade expressa, sobretudo, pelo uso da primeira pessoa, já induzido, aliás, pela proposta do tema: "O lugar onde (eu) vivo". De fato, as crianças, falando do lugar onde moram, tendem a manifestar seus valores, suas ilusões infantis, seu olhar ingênuo sobre o mundo. Assim, são focalizados a casa, a família, os companheiros, a escola, as brincadeiras e também, como era de se esperar, a amizade, a solidariedade, a união, a esperança de um mundo melhor. Essa pessoalidade se mostra também na afetividade, nas manifestações de amor à terra natal, às vezes ufanista, outras vezes fundada em clichês inespecíficos e idealizações, como nas estrofes do poema 15: 
Exemplo 7 (P15)

(...)

Sua bela paisagem

É muito apreciada

Todos admiram

E falam que é linda

Assim acho meu cantinho

Muito lindinho

Penso que nunca esquecerei

Desse belo lugarzinho!

A presença de elementos inusitados, que qualifica a pessoalidade do texto, se revela em apenas $25 \%$ dos poemas: $21 \%$ com realização razoável e só 4\% com realização adequada (cf. Quadro 1). O inusitado, segundo os critérios observados, quebra as expectativas do leitor, revelando lirismo, ou humor, ou ironia, ou crítica. A possibilidade de romper com as idealizações e falar com "belos versos, como os de Patativa (...) sobre sofrimento e dificuldades" é ressaltada na Oficina 8 (p. 36) e na Oficina 11 (p. 46), que inclui entre seus objetivos "reconhecer os aspectos positivos e negativos do lugar onde vivem". Esse aspecto parece ter sido bem observado por professores e alunos, pois é bastante frequente na amostra e aparece até mesmo em textos de pouca poeticidade e que abrigam clichês, como o P23, a seguir:

\section{Exemplo 8 (P23)}

Eu vivo no Rio Grande do Sul

O céu tão lindo

É tão azul.

Moro em Cachoeirinha

Mas ela não é tão pequenininha

Tem belezas

E tem coisas feias,

Tem gente que destrói a natureza

$\mathrm{E}$ outros que fazem nascer mais belezas.

(...)

Tem casas bonitas e outras feias

Umas são feitas de tijolos

$\mathrm{E}$ outras de madeira. 
(...)

Aqui não é um paraíso

Mas para mim

É muito bom assim.

A postura crítica pode ser também exemplificada em versos mais bem-realizados, como em P246, no qual a criação de antíteses abriga a visão crítica, o inusitado, o humor e até mesmo a melancolia da solidão:

\section{Exemplo 9 (P246)}

O prefeito é legal

$\mathrm{Na}$ eleição

Vira cara de pau.

Minha professora é inteligente

Também brinca

Com a gente.

A polícia é exigente

Tem vezes

Que prende inocente.

$\mathrm{Na}$ minha rua

Temos vizinhos

Mas eu brinco sozinho.

Como se viu no Quadro 1, o emprego de rimas é o traço mais frequente nos poemas examinados, presente em 93\% deles. Os 7\% de ausência desse quesito significam a opção por versos brancos, embora se tenha constatado que nem sempre essa opção se traduza em trabalho poético na composição. Muitas vezes, os versos apenas correspondem a linhas na folha de papel, outras vezes, nem sequer há versos.

A maioria dos poemas (65\%) faz uso de rimas simples e fáceis ou adota combinações forçadas, por vezes descabidas, para obter a rima desejada. Além do exemplo já visto na análise da poeticidade (P194), podemos ilustrar essas afirmações com um caso significativo: o poema 12 , a seguir, em que a tentativa de encontrar rimas, ainda que toantes, além de prejudicar o ritmo, resultou em um texto desconexo. 


\section{Exemplo 10 (P12)}

\section{Minha rua}

O lugar onde vivo

Tem muitas casas

Uma delas é a minha

E todas sempre arrumadas

Minha rua é legal

Também especial

Minha casa é amarela

E gosto muito de lápis de cor aquarela

Também tenho um jardim

E um benjamim

A minha vizinha

É a Nelizinha

Ela é legal

E às vezes essencial

(...)

O meu vizinho

Se chama Nelsinho

Gosto muito dele

Porque ele é especial

E bacanal

(...)

Moro perto do fórum

E tenho um amigo

Que se chama Górom

(...)

Entre os 28\% poemas bem-avaliados quanto à rima estão os que tomam como padrão os versos de cordel. Nesses casos, mesmo que previsíveis, as rimas seguem um esquema regular, que confere ao poema bom ritmo e, quase sempre, boa métrica.

Bom exemplo de utilização do modelo dos poemas de cordel é o P191, do qual são transcritos alguns versos. Este poema ilustra também a realização de boa caracterização da cidade tematizada, pela apresentação de peculiaridades do lugar onde vive o autor. 


\section{Exemplo 11 (P191)}

Limoeiro, meu encanto

(...)

Aqui nós temos açudes

Onde o homem vai pescar

Para alimentar a família

Você pode acreditar,

Usa galão e tarrafa

Linha, anzol e o landuá.

O pescador corajoso

Sai de casa à noitinha,

Só volta de madrugada

Com bolsa bem cheinha,

Piranha e tucunaré

Piau, tilápia e sardinha

(...)

Aqui se planta e colhe

Quando a chuva cai no chão

O sertanejo depressa

Vai cuidar da plantação

Planta abóbora e melancia

Milho, batata e feijão.

(..)

A presença e qualidade da métrica ou do ritmo foi o segundo quesito mais frequente, ainda que esteja ausente em 19\% dos textos da amostra. Esses casos se referem à má qualidade do uso desse recurso, posto que, mesmo que o autor opte por versos sem métrica regular, seu poema há de ter ritmo, seus versos livres hão de ter alguma "melodia" que expresse o casamento entre "conteúdo" e "forma".

Um exemplo da possibilidade desse feliz casamento, num poema de versos brancos e livres, é o P70, transcrito a seguir. Em intertextualidade com "Cidadezinha qualquer", de Drummond, o autor descreve sua rua de maneira bem-humorada e com bons efeitos poéticos. Os versos não rimam, mas o ritmo é bom. 
Exemplo 12 (P70)

Uma rua bem movimentada, Com moradores alvoroçados...

Várias motos em alta velocidade,

Carroças em mínima velocidade.

Crianças brincando,

Cachorros latindo.

Bananeiras, mangueiras,

Macieiras...

Humm... pomar à vista.

Outro exemplo de boa realização do ritmo, dessa vez com versos curtos, quase todos monossintagmáticos é P36, abaixo. O poema é surpreendente, inusitado, pela descrição lacônica, pelo efeito lúdico da licença poética quanto à concordância nominal e pela imagem criada na estrofe final:

\section{Exemplo 13 (P36)}

\section{O lugar onde vivo}

Um pátio,

Uma casa,

Uma horta,

Um galpão,

Um portão e...

dois cão.

Um banheiro,

Um lixeiro,

Quatro quartos,

Uma cozinha, uma sala e...

Um pote de balas.

Alface, cebola, tomate, pimenta, Couve e chuchu...

- repousando tranqüilo -

Como o lugar onde vivo. 
No entanto, há muitos exemplos de textos que revelam as dificuldades dos alunos na criação e na manutenção do ritmo. Alguns deles quebram o ritmo tentando obter uma rima; outros não conseguem imprimir ritmo aos versos brancos e livres, como se vê nos exemplos a seguir.

\section{Exemplo 14 (P208)}

A paz nunca deixou de existir Somos nós que não conseguimos a enxergar A pessoa que gosta de matar (..)

Exemplo 15 (P196)

(...)

As flores e o mar

Me fazem cantar

Na cidade de Macapá

Estudo lá na Santina Rioli eu quero estar.

Bateu meu coração quando senti o chão

(...)

Um problema muito encontrado na amostra constitui um desrespeito ao que se poderia chamar de "convenção social" quanto ao modo de ler e escrever poema: o aluno autor, não atentando para a organização dos versos quando da mudança de linha, realiza translineação indevida e, com isso, causa prejuízos de natureza formal e poética ao texto. Muitos casos poderiam ilustrar o problema descrito; trazemos aqui apenas um exemplo.

\section{Exemplo 16 (P142)}

Hortolândia traz sinais de re-

beldia

Mas as pessoas que nela vi-

vem

(...)

Meu bairro é quase fora da

linha

Fica na escolha de caminhos

(...) 
A esse respeito, o P49, próximo exemplo, evidencia uma questão interessante. Parece que os alunos têm boa intuição quanto à métrica dos versos mais populares, de sete e quatro sílabas poéticas, mas não sabem traduzi-la na folha de papel. Um dos efeitos dessa linearização que parece inadequada é a produção de rimas internas, contraposta à perda de rima no final dos versos e à consequente quebra (indesejada?) do ritmo.

\section{Exemplo 17 (P49)}

(...)

De manhã bem cedinho me levanto,

Escuto o canto dos galos e dos passarinhos

Me chamando a passear, olho e vejo

Tanta beleza, vejo pássaros a voarr,

Vejo flores lindas e perfumadas,

Abelhas e beija-flores, o seu néctar a sugar!

Olho para o horizonte, ao longe vejo as fontes

Gados e montes, matas e rios,

Sinto a brisa fria o meu corpo tocar!

Andando pelos campos e bosques,

Colhendo fruta madura, doce como o mel

De sabor bem agradável, andando de pé descalço

Banhando nas águas dos rios.

(...)

Apesar de todos os problemas apontados, rima e ritmo foram os fatores de pertinência ao gênero poema mais presentes e bem-realizados na amostra. Esse resultado quantitativo e qualitativo corresponde ao que deveria ser esperado, posto que, nas práticas culturais mais cotidianas, a que todos os alunos têm acesso, estão fortemente presentes padrões textuais da família do poema (cordel, trovinha, parlenda, cantiga de roda, letra de música popular) cuja marca identificatória são a rima e o ritmo. $\mathrm{Na}$ linguagem corrente, aliás, rimar é sinônimo de "fažer poesia".

Os componentes que chamamos aqui de poeticidade e pessoalidade são mesmo mais distantes do senso comum sobre poesia, principalmente no que se refere à nossa expectativa de originalidade e rompimento com o clichê e o lugar-comum. 


\section{Considerações finais}

Fechando esta análise da adequação dos textos da amostra ao gênero poema, algumas afirmações podem ser feitas.

De início, cabe salientar que a proposta de atividade apresentada nos fascículos relativiza algumas noções, como a de poema, e deixa de explorar adequadamente outras, na medida em que, por meio das atividades indicadas nas oficinas, de algum modo não possibilita a superação da dicotomia conteúdo-forma.

Pode-se dizer, igualmente, que os textos dos alunos aproximam-se do que é próprio do gênero poema, apresentando características reconhecidas como pertinentes a esse gênero, como disposição em versos e estrofes, construção de rimas, busca de ritmo adequado. Grande parte deles se vale do recurso da repetição, criando um refrão que evidencia o elo entre as estrofes e favorece o ritmo. Essas características, bastante frequentes na amostra, revelam conhecimento do gênero na sua modalidade mais presente na cultura popular e na tradição oral, musicada ou não, e evidenciam a tentativa de realizar textos pertinentes a esse gênero.

Assim, o saber tradicional prevaleceu sobre os conceitos e recomendações das Oficinas do Poetas da escola 2006. Alunos e professores parecem saber lidar melhor com a dimensão formal mais reconhecida e perceptível dos poemas (rima e ritmo) do que com o trabalho linguístico mais elaborado de criação de imagens e utilização de recursos sonoros mais sofisticados. E, além disso, tanto os alunos autores quanto os professores que os orientaram e selecionaram seus textos revelaram ter facilidade maior em encontrar rimas do que em construir métrica regular ou bom ritmo para seus poemas.

Dos dois recursos sonoros trabalhados no fascículo, a repetição está presente nos poemas com frequência bem mais alta que a aliteração. Embora esse dado não tenha recebido tratamento quantitativo, é possível afirmar com segurança que a repetição é muito recorrente nos textos, por meio da criação de refrões que são retomados a cada estrofe. O grande e inequívoco exemplo é a repetição da frase tema do concurso, tomada como título e como verso.

Também com relação à criação de imagens poéticas, prevalece na amostra a estética culturalmente mais arraigada, que privilegia a idealização, o clichê, o lugar-comum, em função de uma compreensão estereotipada do belo e daquilo que pode ser tema de poesia. 
Assim, são pouco frequentes na amostra características que requerem maior elaboração da linguagem e que são recomendadas nas oficinas do fascículo Poetas da escola 2006, como a recriação da realidade por meio de comparações, metáforas e outras figuras, ou como a exploração do recurso fônico da aliteração.

$\mathrm{Na}$ análise do item "pessoalidade", constatamos que são pouco frequentes as marcas de autoria. $\mathrm{Na}$ amostra, o previsível superou o inusitado, o clichê superou a expressão de um olhar pessoal, a reprodução da proposta de tema rivalizou com a elaboração original de título e suplantou a criação de título expressivo.

Uma das principais características dos textos analisados, além das que já foram apontadas acima, é ater-se ao tema previsto: $90 \%$ dos poemas falam do lugar onde vive o aluno autor. Entretanto, cerca de 70\% são descrições impessoais que não se aplicam a um espaço-tempo peculiar, não caracterizam efetivamente o lugar tematizado. Assim é que a idealização e o clichê acabam comprometendo as marcas de autoria nos poemas.

A análise qualitativa dos textos, sobretudo nos momentos de retomada para escolha de exemplos, revelou que são raros os casos "absolutos”, isto é, que realizam integralmente um dos critérios e, também, que o contrariam em toda a extensão do poema. Num poema de bom ritmo, pode e costuma aparecer um ou mais versos "de pé quebrado"; por outro lado, um texto recheado de clichês pode trazer um "achado", uma imagem comovente ou inusitada. Enfim, qualidades e problemas co-ocorrem em grande número de textos examinados. Essa constatação nos remete a outras reflexões.

É historicamente recente a proposta de trabalho com gêneros textuais na escola; essa tendência não se respalda em tradição pedagógica já estabelecida e constitui novidade incompreendida para grande parte dos professores. Outras pesquisas já revelaram a força de compreensões equivocadas dessa proposta, que se efetivam, por exemplo, em atividades de definição e reconhecimento de gêneros, no trabalho limitado à forma composicional. Assim, é provável que muitos dos professores que inscreveram seus alunos no PEF 2006 não tenham familiaridade com o gênero escolhido e, por isso mesmo, os resultados aqui debatidos devem ser vistos como um momento de transição, em que o professor já procura seguir as recomendações do respectivo fascículo, mas ainda convive com práticas tradicionais. 
Os alunos autores dos textos analisados, por sua vez, são crianças, com idade em torno dos 10-12 anos, que cursavam a $4^{\mathrm{a}}$ ou a $5^{\mathrm{a}}$ série do Ensino Fundamental em 2006 e que representam a grande diversidade cultural, social e econômica dos muitos "lugares" que abrigam as escolas públicas participantes do PEF 2006. Nesse quadro, parece-nos que seria imprópria a expectativa de encontrar textos plenamente adequados ao gênero poema, tal como entendido e valorizado na esfera literária. Os resultados obtidos não se mostram distantes do que seria esperável.

\section{Notas}

${ }^{1}$ A origem deste artigo é um relatório avaliativo apresentado à Fundação Itaú Social e ao Centro de Estudos e Pesquisas em Educação, Cultura e Ação Comunitária - CENPEC, em dezembro de 2007, a respeito dos fascículos do Programa Escrevendo o Futuro (terceira edição, 2006-2007), que propõem oficinas de escrita, e dos textos dos alunos produzidos nesse contexto. As análises apresentadas neste trabalho são de inteira responsabilidade das autoras. ${ }^{2}$ Para um aprofundamento da questão, veja-se a obra de MEURER, José L.; BONINI, Adair; MOTTA-ROTH, Désirée (Orgs.). Gêneros: teorias, métodos, debates. São Paulo, Parábola, 2005.

${ }^{3}$ MARCUSCHI, Luiz A. Gêneros textuais: o que são e como se constituem. Recife: UFPE, 2002. (Mimeo.)

${ }^{4}$ MILLER, Carolyn R. Genre as social action. In: FREEDMAN, A.; MEDWAY, P. (Eds.). Genre and the New Rhetoric. Londres: Taylor \& Francis, 1994 [1984]. p. 23-42.

${ }^{5}$ BRONCKART, Jean-Paul. Atividades de linguagem, textos e discursos. Por um interacionismo sócio-discursivo. São Paulo: Editora da PUC-SP, EDUC, 1999.

'BAZERMAN, Charles. Gêneros textuais, tipificcașão e interação. São Paulo: Cortez, 2005.

7 BUNZEN, Clecio. O ensino de "gêneros" em três tradições: implicações para o ensino-aprendizagem de língua materna. In: COVRE et al.. Quimera e a peculiar atividade de formalizar a mistura do nosso café com o revigorante chá de Bakbtin. São Carlos: Grupos de Estudos dos Gêneros do Discurso, p. 221-257, 2004.

${ }^{8} \mathrm{O}$ presente artigo se atém, a partir de agora, ao estudo de textos escritos.

9 ROJO, Roxane. Gêneros de discurso / texto como objeto de ensino de línguas: um retorno ao trivium? In SIGNORINI, I. (Org.). Re]discutir texto, gênero e discurso. São Paulo, Parábola: 2008. p. 73-108.

${ }^{10}$ Este tipo de regularidade favorece a estabilidade dos gêneros textuais em determinado contexto sociocultural, o que não impede, obviamente, que o autor recorra à intergenericidade (MARCUSCHI, 2002) ou realize "transgressões" no texto.

${ }^{11}$ Relatório a respeito do desempenho dos alunos no gênero memórias foi desenvolvido pelos professores Acir Karwoski e Vera Lúcia Lopes Cristóvão, e no gênero artigo de opinião, pelas professoras Ângela Kleiman e Maria Luiza Coroa. 
ALTENFELDER, Anna Helena. Poetas da escola. Prêmio Escrevendo o Futuro. Fundação Itaú Social. CENPEC. 3 ed. São Paulo, Peirópolis. Fascículo, 2006.

${ }^{13}$ Em 2008, a configuração do PEF mudou e, associado às Olimpíadas da Língua Portuguesa, atingiu, naquele ano, alunos dos: quinto e sexto anos (gênero poema); sétimo e oitavo anos (gênero memórias); segundo e terceiro anos do Ensino Médio (gênero artigo de opinião).

${ }^{14}$ No levantamento dos dados aqui analisados, contamos com a preciosa colaboração da professora Guilhermina Pereira Corrêa (FIBRA/PA).

${ }^{15}$ Os exemplos são indicados por um $\mathrm{P}$ (gênero poema) seguido do número atribuído ao texto do aluno.

\section{Referências bibliográficas}

ALTENFELDER, Anna Helena. Poetas da escola. Prêmio Escrevendo o Futuro. Fundação Itaú Social. CENPEC. 3 ed. São Paulo: Peirópolis, 2006. Fascículo.

BAZERMAN, Charles. Gêneros textuais, tipificação e interação. São Paulo: Cortez, 2005.

BRONCKART, Jean-Paul. Atividades de linguagem, textos e discursos: por um interacionismo sócio-discursivo. São Paulo: Editora da PUC-SP, EDUC, 1999.

BUNZEN, Clecio. O ensino de "gêneros" em três tradições: implicações para o ensinoaprendizagem de língua materna. In: COVRE et al. (Org.). Quimera e a peculiar atividade de formalizar a mistura do nosso café com o revigorante chá de Bakhtin. São Carlos: Grupos de Estudos dos Gêneros do Discurso, 2004. p. 221-257.

MARCUSCHI, Luiz A. Gêneros textuais: o que são e como se constituem. Recife: UFPE, 2002. (Mimeo.)

MEURER, José L.; BONINI, Adair; MOTTA-ROTH, Désirée (Orgs.). Gêneros: teorias, métodos, debates. São Paulo: Parábola, 2005.

MILLER, Carolyn R. Genre as social action. In: FREEDMAN, A.; MEDWAY, P. (Eds.). Genre and the New Rhetoric. London: Taylor \& Francis, 1994 [1984]. p. 23-42.

ROJO, Roxane. Gêneros de discurso / texto como objeto de ensino de línguas: um retorno ao trivium? In: SIGNORINI, I. (Org.). Re]discutir texto, gênero e discurso. São Paulo: Parábola, 2008. p. 73-108.

Endereço para correspondência: Universidade Federal de Minas Gerais (UFMG)

Faculdade de Educação ( $\mathrm{FaE})$

Av. Pres. Antonio Carlos, 6627

$31270-901$

Pampulha

Belo Horizonte - MG

Data de recebimento: 26/09/2008

Data de aprovação: 23/09/2009 